\title{
Carl Schmitt, enemigo de sí mismo
}

\author{
Carl Schmitt: himself as his Ownmost Enemy
}

\author{
Eduardo Sabrovsky*
}

Universidade Diego Portales, Santiago, Chile

\section{Resumen}

En este artículo me propongo dar razón de la falta de coherencia que afectaría al pensamiento de Carl Schmitt, y que se haría evidente, tal como lo desarrollo, ya en el paso de Teología Política a El Concepto de lo Político. En lo fundamental, intentaré mostrar cómo Schmitt, en su intento por volver contra el mundo y el estado modernos la idea de soberanía pensada bajo la lógica de excepción, no advierte que tal lógica es inherente a aquello mismo que deplora. Más precisamente, mediante dicha lógica Schmitt apunta hacia aquello que, bien entiende, sería la base del mundo moderno y de su racionalidad: la exclusión de lo absoluto, el consiguiente relativismo. Pero no advierte que esta exclusión es, a la vez absoluta, de modo que lo absoluto ha sido desplazado al lugar paradójico de la excepción. Así, queda atrapado por aquello que él mismo, en su El concepto de lo político, denomina "la asombrosamente consistente sistemática del pensamiento liberal". Pues sólo de la muy moderna y absoluta (y paradójica) exclusión de lo absoluto - de lo absoluto en cuanto fundamento positivo, al cual se podría apelar para fundar una concepción positiva de lo político - se sigue que la razón suficiente de la regla, que

* ES: Doutor, e-mail: eduardo.sabrovsky@mail.udp.cl 
la confirma y da vida, sólo pueda ser pensada como excepción. Con esto, excepción y regla devienen correlatos: aquélla sólo puede existir, en tanto excepción, a través de ésta; a su vez, la inmanencia de las reglas que constituyen el espacio político moderno no es ni podría jamás ser completa, de modo que el mismo afán de completarla pone en evidencia su incompletitud, la fisura a través de la cual se abre hacia la exterioridad de la excepción.

Palabras claves: Teología política. Modernidad. Excepción. Paradoja. Soberanía.

\section{Abstract}

My purpose in this essay is to critically account for the lack of internal coherence affecting Carl Schmitt's oeuvre, a lack that an in-depth comparison between Political Theology and The Concept of the Political is enough to establish. In short, I shall try to show how, in his attempt to turn the idea of sovereignty, conceived under the logic of the exception, against the modern world and its political organization, Schmitt disregards the way in which that logic is, on the contrary, inherent to the object of his rejection. More precisely, with the means of that logic, Schmitt aims at what he correctly understands is the ground of the modern world and its rationality: the exclusion of the absolute and its consequence, the ensuing relativism. But he disregards the complexity of this ground and of its relation to the absolute. Because this exclusion is, itself, absolute, so that the absolute has rather been evacuated to the paradoxical locus of the exception. In this way, and against himself, Schmitt remains under the spell of "the incredibly coherent systematics of liberal thought.' Because only the modern, and paradoxical exclusion of the absolute - of the absolute as a positive ground, that might provide the foundation for a thoroughly positive conception of politics - can transform the exception into the rule's sufficient reason. With this, exception and rule become correlates: the former can only exist, as exception, through the latter. At the same time, the immanence of the rules that make the modern political space is never complete; the very effort to complete it discloses its inherent incompleteness, the crack through which it surrenders to the exteriority of the exception.

Keywords: Political Theology. Modernity. Exception. Paradox. Sovereignty. 


\section{Introducción}

'El enemigo es la forma de nuestra propia pregunta.'

(Verso de un poema de Theodor Däubler, citado con frecuencia por Carl Schmitt).

En un ensayo incluido en una colección de textos sobre la cuestión del mito y lo político en Carl Schmitt, Yves Charles Zarka examina lo que denomina la "triple traición" (teológico-política; jurídicopolítica; ético-política) de Schmitt a un pensador, Hobbes, del cual, sin embargo, se declara seguidor ${ }^{1}$. Y tal traicionera trinidad proyectaría su sombra, entre otros, sobre el célebre documento - documento y no obra - que Schmitt publica en 1938, El Leviathan en la doctrina del estado de Thomas Hobbes ${ }^{2}$.

Zarka encuentra la raíz común de esta "triple traición" en el antisemitismo de Schmitt: una causa extrínseca que estaría en la base de su antiliberalismo. Más precisamente, esta causa estaría operando en cada una de las tres traiciones: 1) como tergiversación de la interpretación de Hobbes acerca del "estado de los hebreos" ( "si hay, para Hobbes, un pueblo que promovió la figura prototípica del Estado soberano, es

1 Cito el texto de Zarka según traducción al castellano (ZARKA, 2010), con ocasionales modificaciones teniendo en cuenta la versión original francesa (ZARKA, 2009).

2 La distinción entre "obra"y "documento" se encuentra también en el texto de Zarka que cito. Escribe: "[habría] que distinguir las producciones intelectuales en dos clases: obras y documentos... Cuando digo que los textos de Schmitt no son más que documentos, no entiendo que puedan ser sólo objeto de abordaje histórico, y no filosófico. Un documento puede, por supuesto, ser objeto de un estudio tanto histórico como filosófico. Es evidente que hay un recorte parcial entre la categoría de documento y la de obra. Pero lo que hace al carácter particular del documento es estar inscripto en un momento histórico del cual no es más que un testimonio. Es, de algún modo, inseparable de aquél. Por el contrario, una obra nos interpela, más allá del tiempo, fuera del contexto en que ha sido escrita para hablar tanto de su tiempo como del nuestro. En este sentido, Hobbes fue el autor de una obra, mientras que Schmitt es el autor de documentos." (ZARKA, 2010, p. 37-38). Suscribo esta distinción de Zarka; entiendo que Schmitt está impedido de producir una "obra" por un síntoma (el antisemitismo) que escapa a su capacidad de auto-esclarecimiento. No obstante, mi elaboración comienza donde la de Zarka termina. Me propongo llevar la discusión acerca de la falta de coherencia y sistematicidad del pensamiento de Schmitt hasta el núcleo metafísico de su teología política; hasta "la metafísica [que es] la expresión más intensa y clara de una época", como escribe el propio Schmitt en Teología política (SCHMITT, 2009, p. 44). Algunos años más tarde, en plena elaboración de su "historia der ser" (Seinsgeschichte), Martin Heidegger se expresará en términos semejantes: "la metafísica fundamenta una época" (HEIDEGGER, 1995, p. 75-109). Siguiendo a Heidegger, es allí, en tal metafísica, donde obra y documento histórico, necesidad y contingencia, convergen en una historicidad primordial (la de los "tiempos modernos"). 
el pueblo judío", apunta Zarka contra Schmitt³); 2) como identificación de la soberanía con la dictadura y la excepción ("La soberanía, ...en Hobbes, no se define por la excepción ni desemboca en una teoría de la suspensión del orden jurídico; por el contrario, tiene la función de subsumir la excepción bajo la regla general y de asegurar la permanencia del orden jurídico", apunta nuevamente Zarka ${ }^{4}$ ); 3) finalmente, y en relación con el punto anterior, la soberanía, en tanto subsunción de la excepción bajo la regla, no se opone a la apertura de espacios para la libertad de conciencia; estos espacios serían, no resquicios a través de los cuales los pensadores judíos - Baruch Spinoza, Moses Mendelsohn, Friedrich Julius Stahl-Jolson et al. - habrían socavado la construcción soberana; por el contrario, le serían inherentes. Pues para Hobbes, anota Zarka, "el conjunto del edificio político no merecería un segundo de existencia si no tuviera por finalidad preservar el ser de los individuos que lo componen" (ZARKA, 2010, p. 54) $)^{5}$.

Zarka cita también, a favor de su tesis, un texto poco conocido de Schmitt, "La ciencia alemana del derecho en su lucha contra el pensamiento judío", conferencia de cierre pronunciada por Schmitt en un coloquio que llevó por título "El judaísmo en la ciencia del derecho" (1936). Si ya estos títulos son inquietantes, el texto mismo de Schmitt, tal como Zarka parcialmente lo cita, es un feroz llamado a la limpieza étnica tanto de bibliotecas (donde "todos los escritos de autores judíos deben estar ordenados sin distinción" en una sección de "Judaica") como de la erudición intelectual en su conjunto (Schmitt niega a los pensadores judíos todo tipo de "autoridad científica"; si acaso se lo

3 ZARKA, 2010, p. 45.

4 ZARKA, 2010, p. 49-50. Es necesario agregar, sin embargo, que la inversa también se cumple: el orden jurídico que subsume (o "neutraliza", para usar una expresión Carl-Schmitiana) la excepción no podría sino llevar la huella de ésta, de modo que, como diré más adelante, si la excepción es el milagro, tanto el mundo como el orden de lo jurídico que lo subsumen quedan contaminados por su "milagrosidad", la cual pervive como huella en ellos.

5 En otras palabras, la preservación del fuero interno es un elemento constructivo fundamental del Leviathan: la neutralización/ privatización de toda fe sustantiva, transformada ahora en "creencia" sostenida, sea en el fuero interno del individuo, sea en el de una comunidad de creyentes. Si el Leviathan pretendiese interferir con este fuero, la distinción estructural fuero privado / fuero público se colapsaría, y estaríamos de vuelta al estado de naturaleza.

Rev. Filos., Aurora, Curitiba, v. 29, n. 47, p. 551-574, maio/ago. 2017 
citase, sería indispensable identificar la autoría como judía, para evitar malos entendidos) ${ }^{6}$.

El antisemitismo de Schmitt está bien establecido; Zarka se ha limitado, en este aspecto, a poner de relieve lo que todo lector de Schmitt debiera desde un principio saber. Pero a partir de allí, surge la pregunta: ¿se agota en ello el pensamiento de Schmitt? Más precisamente, ¿cómo se articula, cuál es el rol del antisemitismo en su pensamiento? A continuación pretendo responder estas preguntas, que Zarka no aborda. Mi respuesta consistirá en mostrar que Schmitt, en su intento de volver contra el mundo y el estado modernos la idea de soberanía pensada bajo la lógica de excepción, no advierte que tal lógica - así a continuación lo expongo - es inherente a aquello mismo que deplora. De este modo, Schmitt internaliza a su enemigo; si 'el enemigo es la forma de nuestra propia pregunta', como en el verso de Däubler que gusta citar, a Schmitt tendría que haberle bastado con su imagen en el espejo para encontrarlo. En otras palabras, Schmitt, como muchos de sus contemporáneos y connacionales, habría experimentado el desgarro de pretender negar al mundo moderno recurriendo a la lógica que, precisamente, lo constituye en su núcleo de sentido más primordial; como ellos, sintomatizó este desgarro instaurando al judío como chivo expiatorio. El nacional socialismo se entregó con entusiasmo a la tecnología moderna, a la radio, al cine, a la propaganda, a las supercarreteras, los automóviles para el pueblo y la guerra tecnologizada; a la vez, quiso proclamar el retorno al mundo de la sangre y el mito. Para restablecer su inocencia, era indispensable que el judío, cuerpo extraño o agente modernizador, poco importa, concentrase toda la culpa.

Parto por un somero examen de la historicidad del mundo moderno. La ruptura radical entre la Modernidad y la Cristiandad Medieval es la ruptura entre dos estrategias opuestas para enfrentar lo absoluto. La estrategia medieval lo admitía, pero lo confinaba al espacio de lo sagrado; lo sagrado es aquel espacio - más concretamente, el

6 ZARKA, 2010, p. 38-39. Zarka cita a su vez a Schmitt. El artículo de éste se publicó en Deutsche Jurtisten Zeitung, (20), p. 1193-1199, 15/10/1936. La traducción francesa, que Zarka originalmente cita, corresponde a "La science allemande du droit dans la lutte contre l'esprit juif (SCHMITT, 2003). 
espacio delimitado por los muros de iglesias, catedrales y conventos al interior del cual lo absoluto es venerado, pero también es mantenido a raya, de modo de que su difusión hacia el mundo exterior se mantenga bajo el control de la institución eclesiástica. En términos temporales, esta estrategia de confinamiento tiene su expresión en la escatología: el absoluto puede ser afirmado, siempre y cuando su realización quede postergada para el fin de los tiempos. Los griegos pueden haber seguido una estrategia similar: al dios Pan no se le permitía correr libremente por los campos; para impedirlo, se establecieron misterios y festivales.

Nuestra sociedad secular, en cambio, carece de tales estrategias. Es el producto, precisamente, del derrumbe del confinamiento medieval, y de la elevación de la certeza subjetiva, Reforma Protestante mediante, al sitial de la verdad. En cuanto tal, esta certeza es ilimitada, absoluta $^{7}$. Ante tal desborde incontrolado de lo absoluto - más concretamente, ante la proliferación de sujetos a quienes la Reforma ha investido como poseedores de verdades incondicionales, absolutas - la solución radical es, sencillamente, su expulsión del mundo; en los casos de sujetos recalcitrantes, su confinamiento a esas instituciones, cárceles y asilos, suerte de último refugio de los dioses y de sus iluminados. Y si entendemos por religión el conjunto de prácticas destinadas a tratar con lo absoluto, ésta - la absoluta exclusión de lo absoluto - es el primer y único artículo de fe, el primer y último mandamiento de nuestra religión, la religión de los modernos, que ha venido a sustituir al cristianismo medieval.

Esta religión, tan mínima como exigente, es el ateísmo moderno. Ella contiene, por cierto, elementos de la Reforma, del calvinismo muy particularmente: su Dios no es necesariamente un Dios muerto, como excesivamente lo pretende Nietzsche en su Zarathustra, pero sí un Dios distante, ausente, cuyos designios han dejado de ser conmensurables con el intelecto humano. Pues, ¿cómo podríamos nosotros, míseras partículas de polvo en un rincón alejado del universo,

7 Ver para esto: (POPKIN, 1983). 
pretender que nos habría dado descifrarlos? ${ }^{8}$ El universo ha así desencantado: en él no hay ya formas trascendentes que prefiguren y sirvan de fundamento a aquéllas que el entendimiento humano trabajosamente construye; sólo hay, como en Hobbes, ciega causalidad $\mathrm{o}$, más radicalmente, mero azar ${ }^{9}$.

La vieja teología distinguía entre la potestas absoluta de Dios, en virtud de la cual nada podría restringir su actuar, y su potentia ordinata; en virtud de ella, Dios condesciende a crear una realidad poblada de formas inteligibles, susceptibles de ser traducidas por el entendimiento humano iluminado por la gracia divina - es decir, por la institución eclesiástica - en términos de un orden político y moral que, por provenir de Dios, sería absoluto. La Reforma no admite tal condescendecia. En consecuencia, ya no hay nada que traducir, y la fuente de legitimidad de la institución se desvanece en el aire. La potentia ordinata ha sido transferida, se diría, al ser humano, de modo que, en adelante, el orden será inmanente o no será ${ }^{10}$. A tal historial transferencia reponde el dualismo moderno que postula un mundo humanizado por el despliegue, tendencialmente planetario, de la muy humana voluntad de orden, enfrentado a una realidad entendida como carente en sí misma de forma, de orden y diferenciación: expresión, si se quiere, de la potestas absoluta divina que, ante el ser humano, se hace presente como indiferenciada, entrópica materia prima (la enigmática "cosa en sí" kantiana). Y, precisamente por ello, infinitamente maleable, a priori dispuesta para la forma.

Tal como lo demuestra su célebre polémica con el obispo Bramhall, la construcción hobbesiana del estado moderno reposa sobre,

8 Los lectores de Nietzsche sabrán reconocer aquí la doctrina que éste desarrolla en un escrito temprano, breve - lejos están aún las florituras y excesos de Zarathustra - y genial: "Sobre verdad y mentira en sentido extramoral" (NIETZSCHE, 1999). Todas las citas de textos en idiomas distintos al castellano son de mi traducción (N. del A.)

9 Este es el credo exigente de la ciencia moderna: "La antigua alianza ya está rota: el hombre sabe al fin que está solo en el Universo de donde ha emergido por azar. Igual que su destino, su deber no está escrito en ninguna parte. Puede escoger entre el Reino y las tinieblas." Son las severas, pascalianas palabras con las que el biólogo Jacques Monod (Premio Nobel 1970) concluye su exposición acerca del postulado de objetividad en la ciencia contemporánea, L'hasard et la necéssité. (MONOD, 1970, p. 224-5).

10 Para la distinción teológica entre potestas absoluta y potentia ordinata en Hobbes y en sus adversarios, ver: (FOISNEAU, 2000). 
y refuerza, la transferencia de la potentia ordinata al ser humano moderno; así para Hobbes "no hay nada universal [i.e. nada provisto de forma] en el mundo excepto los nombres; pues las cosas nombradas son, todas y cada una, individuales y singulares" (HOBBES, 1980, p. 24). Es decir, el entendimiento y el lenguaje humano procesan, dan forma 'universal' a una realidad reducida a su sola incidencia sobre los sentidos del sujeto cognoscente ${ }^{11}$. A la vez, al interior del Commonwealth hobbesiano, la administración y neutralización de los efectos potencialmente disruptivos del recurso a lo absoluto, sea por parte de la vieja Iglesia Católica, sea por la de los por entonces llamados "entusiastas", los numerosos poseídos por la divinidad que la Reforma había sembrado por el mundo, es la tarea y el privilegio del soberano.

Más precisamente, frente a esa manifestación paradigmática de lo absoluto en medio del mundo humano, el milagro, Hobbes se comporta a la manera de un ilustrado avant la lettre. Así lo observa Carl Schmitt y se lo reprocha:

El lector del capítulo 37 de su Leviathan ['Acerca de los milagros y su uso'] tiene que aceptar, por lo pronto, que la creencia en los milagros es siempre una superstición...en el mejor de los casos, queda sólo un agnosticismo radical que considera, acaso, posibles algunas cosas, mas ninguna verdadera [...] Nada es verdadero: todo es mandato. Milagroso es todo lo que el poder soberano del Estado manda creer como milagro, pero también a la inversa [...] los milagros dejan de serlo cuando el Estado lo prohibe...Hobbes declara el problema del prodigio y el milagro como negocio propio de la razón 'pública' en oposición a la razón 'privada', pero en virtud de la libertad general del pensamiento [...] queda encomendado a fuero propio de cada cual, conforme a su

${ }^{11}$ La cuestión específicamente moderna del entendimiento humano como portador de formas a priori tiene su expresión paradigmática en Kant. En su Crítica de la Razón Pura, Kant pone explícitamente su tarea en la estela de Hobbes. Escribe: "La crítica, en cambio, que deriva todas sus decisiones según reglas básicas de su propia constitución, cuya autoridad nadie puede poner en duda, nos proporciona la seguridad de un estado legal en el que no debemos llevar adelante nuestro conflicto más que a través de un proceso [...] Los interminables conflictos de una razón meramente dogmática necesitan también buscar, finalmente, la paz en una crítica de esa misma razón y en una legislación basada en ella. Como dice Hobbes, el estado de naturaleza es un estado de injusticia y de violencia, y es preciso abandonarlo para someterse al imperio de la ley, único que limita nuestra libertad de forma que pueda coexistir con la de todos los demás y, por ello mismo, con el bien común." (KANT, 1978, p. 598) (A751/B779-A752/B780). 
razón privada, creer o no creer íntimamente y conservar en su corazón, 'intra pectore suum', su propio 'judicium'. Ahora bien, cuando se llega a la confesión externa de la creencia, el juicio privado nada cuenta y el soberano decide sobre lo verdadero y lo falso (SCHMITT, 2002, p. 53).

Y, en efecto, el soberano hobbesiano, o bien actúa, él mismo, como una suerte de pararrayos que captura, conduce y procesa toda eventual irradiación proveniente de lo alto (de paso, volviendo irrelevante la pregunta por la realidad de aquello); o bien asegura que el milagro quede confinado a la creencia y la interioridad, sea del sujeto individual, sea de la comunidad de creyentes. Escribe Hobbes al cierre del Cap. 37 de su Leviathan:

Un hombre particular (puesto que el pensamiento es libre) tiene siempre la libertad de creer o no creer íntimamente ciertos actos que han sido presentados como milagros, considerando, según su propio testimonio, qué beneficio puede derivar, de la creencia de los hombres, para aquellos que lo reconocen o lo combaten, y conjeturar a base de ello si son milagros o mentiras. Pero cuando se llega a la confesión de esta fe, la razón privada debe someterse a la pública, es decir, al representante de Dios (HOBBES, 1980, p. 369).

Los reproches de Schmitt, en esta crítica a Hobbes, anteceden allí a sus comentarios acerca del "incansable espíritu judío" y su rol en "la disociacion entre el fuero interno y el externo, la moralidad y el derecho, la opinion interna y el acto externo, así como su contraste entre "la sabiduría alemana" vs. 'la táctica judía de las distinciones". Pero su comprensión tanto de Hobbes como del mundo moderno queda bloqueada por el síntoma. Y lo que torna más espectacular esta sintomatización es el hecho que, en su Teología Política de 1922 Schmitt, como lo expondré en un momento, tenía ya a su alcance los elementos centrales para desarrollar esta comprensión, y alcanzar a la vez una mejor intelección de su propio pensamiento, liberándolo de su interiorización del enemigo y, por consiguiente, del lastre del antisemitismo.

Lo que escapa a Schmitt, más precisamente, es la peculiaridad del absoluto que rige al mundo moderno. 1) Por una parte, un mundo 
regido por la absoluta exclusión del milagro (de lo absoluto) no podría sino serlo, él mismo, de modo eminente; en otras palabras, rechazando absolutamente el milagro, este mundo se constituye en una suerte de agujero negro gravitacional, que recoge y concentra en sí mismo toda milagrosidad. 2) La contraparte de este moderno "ver el mundo como un milagro" 12 es, en términos lógicos, la liberación intramundana del explosivo poder de lo condicionado y relativo. Así, en Hobbes, el movimiento local e infinitesimal, conatus o endeavour, es el principio explicatorio fundamental tanto en el campo de los fenómenos físicos como de los sociales y políticos, desplazando a las explicaciones, de raigambre escolástica, que recurrían a alguna noción de totalidad o finalidad ${ }^{13}$. 3) En el ámbito de lo político, el soberano ha de ser inmanente - su poder deriva, no de lo alto, sino de "un pacto de cada hombre con los demás" (HOBBES, 1980, p. 141) - pero a la vez absoluto. Habita así la zona enigmática de la paradoja: una zona de 'extimidad'14 donde se ubica también el mandamiento moderno, la interdicción absoluta de lo absoluto, que él mismo tiene por misión cautelar. La soberanía en cuanto excluida trascendencia tiene, entonces, el mismo destino que el de los tiempos modernos. Y éste se juega en el despliegue del poder, tornado absoluto, de lo relativo.

12 La expresión es de Ludwig Wittgenstein, en su "Conferencia sobre ética" pronunciada en Cambridge entre 1929 y 1930 (WITTGENSTEIN, 1965, p. 3-12). Allí Wittgenstein explicita la metafísica de su Tractatus Logico-Philosophicus, disertando acerca de aquello de lo cual, según éste, no sería posible hablar. Así, dice, "[... es absurdo decir "la ciencia ha demostrado que no hay milagros". La verdad es que el modo científico de observar un hecho es no observarlo como milagro". En otras palabras, la interdicción del milagro no es una 'consecuencia' de la racionalidad científica, sino que es el a priori que la constituye. Es decir, el milagro no ha sido erradicado, sino más bien desplazado hacia una base que permanece sumergida. La punta del iceberg es la interdicción del milagro; su contraparte fundamental es, Wittgenstein nuevamente, "la experiencia de ver el mundo como un milagro" (WITTGENSTEIN, 1965, p. 11). En otras palabras, Wittgenstein comprende que la modernidad científica no se distingue por haber erradicado al milagro, sino que por haberlo concentrado en un punto: en la interdicción que la rige.

13 "Primeramente, defino Endeavour como el movimiento realizado en menor espacio y tiempo que el que puede ser dado; esto es, menor que lo que puede ser determinado 0 asignado mediante exposición o número; es decir, movimiento efectuado a través de la longitud de un punto, y en un instante puntual del tiempo". (HOBBES, 1889, p. 206). Para una discusión del concepto de conatus o endeavor, ver: (Barnouw, 1992, p. 103-124).

14 El término "extimidad" (extimité), patrimonio del psicoanálisis lacaniano, designa precisamente esta zona, la de "una excluida interioridad; un íntimo exterior", en expresión de Jacques-Allain Miller (1994).

Rev. Filos., Aurora, Curitiba, v. 29, n. 47, p. 551-574, maio/ago. 2017 
En virtud de este poder, las sociedades modernas se diferencian y se articulan en sub-sistemas que operan, autónomamente, según una legalidad propia: derecho, educación, ciencia y tecnología, economía, arte y literatura reconocen criterios de pertinencia y validez que les son específicos ${ }^{15}$. Pero en cada una de estas legalidades locales es posible reconocer el eco distante de un evento radicalmente heterónomo, originario e incondicional: así, lo absoluto queda inscrito, incluido en cada uno de los subsistemas que, sin embargo, lo neutralizan y excluyen ${ }^{16}$.

La extimidad da cuenta del carácter enigmático de lo político moderno: de su carácter teológico, tal como Carl Schmitt lo entrevió, aunque de inmediato lo redujo a una tesis sobre la secularización entendida como argumento crucial en una causa abierta contra la legitimidad del mundo moderno ${ }^{17}$. Ésta, como se sabe, es la tesis con que se inicia el tercer capítulo de Teología Política (capítulo fundamental, lleva el mismo título del libro). No obstante, ya en el primer capítulo, y más adelante en el tercero, el propio Schmitt articula, sin saberlo, el fundamento metafísico de aquello que su tesis de la secularización quiere negar, "la legitimidad del mundo moderno".

Pues este fundamento no es otro que la célebre tesis según la cual la excepción hace posible la norma. Escribe Schmitt:

15 El ejemplo paradigmático de este poder de lo relativo es la economía de mercado. Como lo observó reiteradamente Friedrich von Hayek en sus escritos, la superioridad de la economía de mercado en relación a cualquier problemática planificación central consistiría en que, a falta de una 'inteligencia central' (una falta debida a la misma complejidad de la sociedad moderna), el mercado permitiría a los individuos tomar decisiones con un mínimo de información local. Ver para esto por ejemplo (HAYEK, 1945). Von Hayek, sin embargo, no observó que, recíprocamente, a la vocación por lo relativo, que prescinde de la totalidad, esta termina haciéndosele presente bajo la forma de externalidades negativas, desechos (por ejemplo, gases de efecto invernadero) que, tarde o temprano, amenazan la vida humana a nivel planetario, y cuyo control mediante la lógica del mercado es, en estricto rigor hayekiano, imposible.

${ }^{16}$ Utilizo ex-profeso el término "neutralización", perteneciente al léxico de Schmitt, de modo de mostrar que, pensado en su lógica, no implica necesariamente "despolitización", como Schmit lo pretende. Por el contrario, se trata más bien de la modalidad específica de lo político bajo condiciones modernas.

17 Pero teología política y secularización no se oponen, por el contrario: en ambos casos, lo que está en juego es la cuestión del origen del mundo moderno y de su legitimidad. Para una revisión panorámica del rol de la teología en el giro desde el medievo a la modernidad y en sus posteriores consecuencias, ver: (GILLESPIE, 2008). En el'Prefacio', Gillespie discute la tesis de la secularización (aunque sin mencionar a Schmitt). 
La excepción es más interesante que el caso normal. Lo normal nada prueba; la excepción, todo; no sólo confirma la regla, sino que ésta vive de aquélla. En la excepción, la fuerza de la vida efectiva hace saltar la costra de una mecánica anquilosada en repetición [...] el estado de excepción tiene en la jurisprudencia análoga significación que el milagro en teología (SCHMITT, 2009, p. 20-37).

A lo largo de su obra, Schmitt intentará blandir este fundamento metafísico del mundo moderno en contra del mundo moderno; de este modo, mientras más su pensamiento se opone a éste, más queda atrapado en lo que constituye su principio más fundamental.

En efecto: mediante la lógica de la excepción Schmitt apunta hacia aquello que, bien entiende, es la base del mundo moderno y de su racionalidad: la exclusión de lo absoluto, el consiguiente relativismo. Pero no advierte que esta exclusión es, a la vez absoluta, de modo que lo absoluto ha sido desplazado al lugar paradójico de la excepción y del fundamento. Enfrentado a esta paradójica exclusión, el jurista católico que Schmitt quiso ser oscila entre la reivindicación de la plena e ineludible presencia de la revelación como ultima ratio de lo político, y el reconocimiento de que tal cosa ya sólo puede ser pensada bajo la lógica de la excepción ${ }^{18}$. En otras palabras, Schmitt tampoco quiere ser un mero reaccionario, y no puede sino pensar al interior del horizonte de

18 Esta oscilación se puede advertir claramente en un escrito temprano (1923), en el que Schmitt critica agudamente el relativismo del mundo moderno, contraponiéndole la idea de absoluto que presidiría tanto la infalibilidad del Papa como la autoridad terrenal de la Iglesia Católica (SCHMITT, 1996). Como siempre, las observaciones de Schmitt son penetrantes, plenas de actualidad e interés. Pero están enturbiadas por su mala intelección del núcleo metafísico del mundo moderno. Así, en este escrito Schmitt va expandiendo su diagnóstico, descendiendo desde su crítica a la desconfianza moderna en el catolicismo a la crítica a las formas modernas de pensar y a lo que considera sería (por esos años) el rechazo, por parte de los jóvenes bolcheviques, de toda 'idea', en provecho de un modo 'económico-técnico de pensar' (al parecer, Schmitt se refiere a la crítica marxista a la ideología, entendida como mera 'falsa conciencia'). Y escribe: “Mientras siquiera el fantasma de una idea exista, así también sucederá con la noción de que algo ha precedido a la realidad dada de las cosas materiales - que hay algo trascendente - y esto significa siempre una autoridad desde lo alto" (SCHMITT, 1996, p. 27). Schmitt tiene razón, en cuanto lo absoluto no está explícitamente presente en muchos estratos de la racionalidad moderna. Pero no advierte que de ahí no se sigue que el mundo moderno carezca de un mandato absoluto: el mismo Schmitt, en el mismo escrito, observa que "la sociedad europea moderna tiene su propia religión [. . . ] su religión de la privacidad sin la cual la estructura de este orden social se colapsaría" (SCHMITT, 1996, p. 28). Por otra parte, lo que cabría llamar 'olvido de lo absoluto' no es privativo del mundo moderno; Schmitt reconoce que algo semejante puede sucederle al catolicismo - ¡pero como deformación! - a

Rev. Filos., Aurora, Curitiba, v. 29, n. 47, p. 551-574, maio/ago. 2017 
la racionalidad moderna ${ }^{19}$. Pero así es como queda atrapado por aquello que él mismo, en su El concepto de lo político, sugerentemente llamará "la asombrosamente consistente sistemática del pensamiento liberal" (SCHMITT, 1998, p. 99) 20. Pues sólo de la muy moderna y absoluta (y paradójica) exclusión de lo absoluto - de lo absoluto en cuanto fundamento positivo, al cual se podría apelar para fundar una concepción positiva de lo político, como confusamente lo pretende Schmitt - se sigue que la razón suficiente de la regla, aquello que la confirma y da vida, sólo pueda ser pensada como excepción. Con esto, excepción y regla devienen correlatos: aquélla sólo puede existir, en tanto excepción, a través de ésta; a su vez, la inmanencia de las reglas que constituyen el espacio político moderno no es ni podría jamás ser completa, de modo que el mismo afán de completarla pone en evidencia su incompletitud, la fisura a través de la cual se abre hacia la exterioridad de la excepción, hacia una trascendencia regida por un principio de incertidumbre (jamás estará allí donde se la busca). Hay lo absoluto - el mandamiento de la religión de los modernos - mas no ya como presencia que pueda

partir del racionalismo organizacional y político de la Iglesia. Este racionalismo, por lo demás, puede ser entendido como uno de los elementos que precursa al mundo moderno.

19 En el capítulo final de Teología Política I ("Contribucion a la filosofía política de la contrarrevolución (De Maistre, Bonald, Donoso (ortés)"), Schmitt hace un nostálgico elogio de "Ios filósofos católicos del Estado, De Maistre, Bonald y Donoso Cortés" en el centro de cuyo pensamiento se encontraría el 'concepto de decisión': "Todos", escribe Schmit, "formulan un dilema magno, cuya rigurosidad más suena a dictadura que a diálogo eterno" (SCHMITT, 2009, p. 49). Pero este elogio está, una vez más, contaminado por el bloqueo de Schmitt ante "la asombrosamente consistente sistemática del pensamiento liberal" (ver siguiente nota). Pues el decisionismo no es más que afirmación de voluntad de poder; es decir, del núcleo más interno de la moderna filosofía del sujeto y de la voluntad. Para esta determinación del pensamiento moderno, ver: (Heidegger, 2013). Se contiene allí la versión, editada por el mismo Heidegger, de las lecciones sobre Nietzsche como pensador de la consumación de la metafísica de la modernidad, que impartió durante la segunda mitad de los años '30, a lo que se agregan algunos textos sobre el mismo tópico redactados entre 1940 y 1946. Por esos años, Heidegger, quien como Schmitt había adherido al nacional-socialismo, intenta tomar distancia mediante, precisamente, una lectura crítica del pensamiento de la voluntad de poder y del decisionismo en Nietzsche. En parte gracias a esta lectura crítica, el pensamiento de Heidegger experimenta un giro hacia la historización radical, hacia su 'historia del ser'; en ésta, el término "decisión" (Entscheidung) pasa a ser entendido a partir de su etimología como Ent-scheidung (scheidung = escisión), esto es como corte, cesura epocal, por sobre cualquier decisionismo (lo mismo ocurre con la etimología de "decisión" en castellano: remite al latín "caedere", corte, cesura). En las decisiones históricamente relevantes, nadie decide; es la excepción la que 'decide' acerca de la soberanía, y no a la inversa.

${ }^{20}$ Las citas de este escrito provienen de esta edición, con ocasionales modificaciones siguiendo el original en alemán: (SCHMITT, 1991). 
ser invocada como fundamento de una política, sino como un continuo diferir de sí misma que, como un torbellino, absorbe y expulsa hacia la región de la ilusión y el mito toda pretensión de positividad.

Una década después de Teología Política, en El Concepto de lo Político, Schmitt parece advertir que lo absoluto como presencia ha dejado ya de ser pensable. Por ello, intenta invertir los términos: no ya lo absoluto como fundamento, sino la distinción amigo / enemigo, supuestamente siempre concreta, como fundamento de un "concepto de lo político" capaz de hacerle frente a la sistemática del pensamiento liberal. El resultado no podía sino ser conceptualmente débil, como la penetrante lectura que Leo Strauss hizo de él lo confirma.

En todo caso, el intento de Schmitt despertó el interés de Strauss y lo movió a escribir su comentario ${ }^{21}$. Éste se inicia observando que, para Schmitt, debiera resultar básico evitar que 'lo político' sea considerado como una más entre las esferas o "provincias" autónomas de la cultura (STRAUSS, 2008, p. 137-138). Y, en efecto, Schmitt había criticado esta idea de autonomía; no obstante, observa también Strauss, habría derivado su "criterio de lo político" (en oposición a una 'definición exhaustiva de lo político, que renunciaría a dar) por analogía con estas esferas. Escribe Strauss:

\begin{abstract}
Así, el criterio de lo moral es la oposición bueno-malo, el de la estética es la oposición bello-feo, etc. Orientándose según esta relación general, Schmitt determina como 'la específica distinción de lo político [...] la distinción amigo-enemigo' (26) [...Y si bien...] la distinción amigo-enemigo 'no es de igual valor ni análoga [...] a aquellas otras distinciones' (27), entender [de este modo] lo político implica una crítica básica de, como mínimo, el concepto de cultura dominante. (STRAUSS, 2008, p. $138-140)^{22}$.
\end{abstract}

21 (STRAUSS, 2008). Este comentario se publicó en 1932, el mismo año de aparición de la primera edición del libro de Schmitt. He regularizado las citas que hace Strauss de Schmitt utilizando la traducción al castellano especificada en la nota anterior, con alguna ocasional modificación teniendo a la vista el original alemán.

${ }^{22}$ La versión del texto de Strauss que estoy citando pone entre paréntesis los números de página que identifican las citas que hace éste del escrito de Schmitt, incluyendo tanto la numeración de la edición alemana como la de una traducción al castellano. Como no es esa traducción la que estoy utilizando aquí, he preferido conservar sólo los de la edición alemana (SCHMITT, 1991). 
Es decir, Schmitt, subordinando todas las demás esferas de la cultura a lo político, habría dejado intacta la idea misma de autonomía, transferida ahora en exclusiva a lo político. En pocas frases, Strauss desarrolla brillantemente lo que Schmitt dejó sin hacer. Escribe:

[...] según el concepto dominante de cultura, no son sólo las diversas 'provincias de la cultura las que son autónomas las unas respecto de las otras, sino que la cultura como un todo es ya previamente 'autónoma', es la creación soberana, el 'producto puro' del espíritu humano [..cultura...] puede significar: vencer a la naturaleza guardándole obediencia (parendo vincere, en palabras de Bacon); entonces la cultura ya no es tanto el cuidado fiel de la naturaleza, sino más bien una lucha dura y astuta contra la naturaleza. Que la cultura se entienda como cuidado de la naturaleza o como lucha contra la naturaleza depende de cómo se entienda la naturaleza: como orden a imitar o desorden que hay que remediar (STRAUSS, 2008, p. 141).

En consecuencia, lo impensado, lo que entonces rige desde la sombra al "concepto de lo político" de Schmitt es, nada más, nada menos, la premisa central del mundo moderno en su versión positiva, no paradójica: el desencantamiento de la naturaleza; la naturaleza desencantada, no como "orden a imitar", sino como "desorden a remediar". Es decir, desorden dis-puesto a priori para la voluntad de orden que, modernamente, ocupa el lugar vacío dejado por la potentia ordinata divina, y que se despliega, preferentemente, como esa misma empresa tecno-científica que Schmitt sin embargo impugna bajo los rótulos de “despolitización' y neutralización".

La distinción amigo/enemigo, como núcleo de este ya fracturado concepto de lo político, está marcada por la misma fractura. Es patente en el texto de Schmitt - Strauss no deja de advertirlo - que con esa distinción instalada como central, lo político en Schmitt se constituye a partir de una inversión del pensamiento de Hobbes: inversión que, no podría ocurrir de otro modo, es a la vez una repetición. Pues, por una parte, el polo activo y determinante de la distinción es la enemistad: 
desde ella se determina quienes son, o no amigos ${ }^{23}$. Por la otra, en palabras de Schmitt "[...] todas las teorías políticas propiamente dichas presuponen que el hombre es 'malo', y lo consideran como un ser no sólo problemático sino 'peligroso' y dinámico” (SCHMITT, 1998, p. 90). Ahora bien: la combinación de enemistad más maldad o peligrosidad se traduce en la posibilidad constante del estallido de la guerra. En suma, Schmitt, invirtiendo a Hobbes, hace equivaler 'lo político' al estado de naturaleza. Y, en efecto, Schmitt escribe:

En este sentido hay que entender en Hobbes, pensador político grande y sistemático donde los haya, en primer lugar, la concepción "pesimista» del hombre; en segundo lugar, su correcta comprensión de que lo que desencadena las más terribles hostilidades es justamente el que cada una de las partes está convencida de poseer la verdad, la bondad y la justicia; y finalmente, en tercer lugar, que el bellum de todos contra todos no es un engendro de una fantasía obcecada y cruel, ni tampoco una mera filosofía de una sociedad burguesa que se está construyendo sobre la base de la libre «competencia» (Tónnies), sino que se trata de presupuestos elementales de un sistema de ideas específicamente político (SCHMITT, 1998, p. 94).

Llama la atención la celeridad con que Schmitt se deshace aquí de Tónnies, sin que la tesis así descartada merezca siquiera una nota al pie, en un texto en el que éstas son abundantes y copiosas, como lo son también los comentarios bibliográficos y eruditos, las aclaraciones y re-elaboraciones (al final de la re-impresión de 1963). Pues una lectura aún somera de los primeros parágrafos del capítulo que Hobbes en Leviathan dedica al estado de naturaleza (o sea: al estado político en Schmitt) hace más que plausible la mencionada lectura de Tónnies.

${ }^{23}$ Escribe Strauss: "De las dos instancias de la perspectiva amigo-enemigo es evidente que la instancia del enemigo tiene la primacía, lo que se desprende ya del hecho de que, al explayarse más en detalle sobre esta perspectiva, en realidad Schmitt sólo habla de lo que significa enemigo (véanse p. 27,29 y 32.). Podría decirse: todo conjunto de individuos busca hacerse de amigos, tiene amigos, justamente por el hecho de que ya tiene enemigos; 'la esencia de las relaciones políticas consiste en la referencia a un antagonismo concreto (p. 30) [... . en el concepto de enemigo' (p. 33) se incluye 'la eventualidad, en términos reales, de una lucha'y a partir de la eventualidad de la guerra, del'caso extremo', de la'posibilidad extrema,' 'la vida adquiere su tensión específicamente política' (p. 35)" (STRAUSS, 2008, p. 140). 
En estado de naturaleza, nos dice Hobbes, los seres humanos son básicamente iguales en cuanto a fuerza corporal y, más aún, en cuanto a las facultades mentales. De esta fundamental igualdad - igualdad, en definitiva, ante la posibilidad de muerte por obra de otro, pero a la cual, sugerentemente, Hobbes denomina "competencia" - Hobbes colige la desconfianza mutua ("de la igualdad procede la desconfianza", subtitula), y de esta, la constante disposición hacia la guerra (HOBBES, 1980, p. 101-102).

Es decir, el ser humano supuestamente natural que Hobbes describe es ya un hombre moderno que emerge del Medioevo a una sociedad carente de jerarquías substantivas; un maximizador racional enfrentado entonces horizontalmente a sus pares. El estado de naturaleza, pace Schmitt, no es sino el resultado del experimento mental de sustraer, del naciente capitalismo moderno, las formas estatales que, aún en su estado incipiente, lo acompañan y constituyen la faz política de un fenómeno historial unitario. Su carácter contrafactual queda a descubierto cuando, un poco más adelante en Leviathan, Hobbes lo caracteriza precisamente de esa forma. Escribe:

En una situación semejante no existe oportunidad para la industria, ya que su fruto es incierto; por consiguiente no hay cultivo de la tierra, ni navegación, ni uso de los artículos que pueden ser importados por mar, ni construcciones confortables, ni instrumentos para mover y remover las cosas que requieren mucha fuerza, ni conocimiento de la faz de la tierra, ni cómputo del tiempo, ni artes, ni letra, ni sociedad; y lo que es peor, existe continuo temor a la muerte violenta; y la vida del hombre es solitaria, pobre, embrutecida, y breve (HOBBES, 1980, p. 103) ${ }^{24}$.

Es cierto que, en principio, en Schmitt el estado de naturaleza - es decir, el estado político - está reservado a las relaciones entre los estados. Pero el efecto antiliberal que quiere lograr con su concepto de lo político no se agota en absoluto allí. Porque de lo que en

24 Hobbes podría haber agregado que en estado de naturaleza, no es posible la "sana competencia" sin que esta derive en guerra. Más atrás (nota 14) he relacionado la liberación del poder, tornado absoluto, de lo relativo, hecha posible por el estado hobbesiano, con la economía de mercado en su versión neoliberal hayekiana. Estado de naturaleza, domesticación por medio de la regulación del estado, capitalismo y economía de mercado, son uno y el mismo fenómeno. 
verdad se trata es de devolver a la vida humana una seriedad perdida, a través de la activación de la enemistad, de la posibilidad de la guerra y del hobbesiano "continuo temor a la muerte violenta". Y en efecto, Schmitt reconoce que la tesis de la peligrosidad del hombre es sólo una "conjetura", una "confesión de fe antropológica" (SCHMITT, 1998, p. 87); por otra parte, tal suposición o profesión de fe, como todo lo que se piensa en el ámbito de lo político, "no tiene un sentido normativo, sino sólo existencial" 25 .

Finalmente, después de seguir las vicisitudes de su "concepto de lo político", hemos llegado a puerto: la base del pensamiento de Schmitt es aquí una filosofía de la existencia ${ }^{26}$. Pues, a través de lo político, de la distinción amigo / enemigo, del privilegio de la enemistad, la confrontación, la posibilidad de la guerra y el peligro de muerte, se trata de vivir peligrosamente, de modo que "la vida adquier[a] su tensión específicamente política" (SCHMITT, 1998, p. 65). Y así, en este Schmitt, se hacen reconocibles las figuras clásicas de la filosofía de la existencia, tales como fueron fijadas canónicamente por su contemporáneo y más tarde camarada Heidegger en Ser y Tiempo y, más atrás, por Nietzsche.

En el caso del primero, Ser y Tiempo se configura a partir de la evidencia de un mundo que se hace presente como una red de equipamiento, de útiles disponibles al cual el Dasein ha sido arrojado, y al cual sólo puede sobreponerse anticipando, precursando su posibilidad más propia, "[1]a muerte [...] como la posibilidad más propia, irrespectiva

25 Conviene citar aquí a Schmitt in extenso: "La guerra, la disposición de los hombres que combaten a matar y ser muertos, la muerte física infligida a otros seres humanos que están del lado enemigo, todo esto no tiene un sentido normativo sino existencial, y lo tiene justamente en la realidad de una situación de guerra real contra un enemigo real, no en ideales, programas 0 estructuras normativas cualesquiera. No existe objetivo tan racional, ni norma tan elevada, ni programa tan ejemplar, no hay ideal social tan hermoso, ni legalidad ni legitimidad alguna que puedan justificar el que determinados hombres se maten entre sí por ellos. La destrucción física de la vida humana no tiene justificación posible, a no ser que se produzca, en el estricto plano del ser, como afirmación de la propia forma de existencia contra una negación igualmente óntica de esa forma. Una guerra no puede justificarse tampoco a base de argumentos éticos y normas jurídicas. Cuando hay enemigos verdaderos, en el sentido óntico al que se está haciendo referencia aquí, tiene sentido, pero sólo políticamente, rechazarlos físicamente, y si hace falta, combatir con ellos" (SCHMITT, 1980, p. 78.).

26 Para una lectura de Schmitt en clave de la filosofía de la existencia, ver: (MARDER, 2010). 
e insuperable"27. En cuanto a Nietzsche, el nihilismo pasivo, la desertificación del mundo - "el desierto crece" (NIETZSCHE, 1967,379) - que se seguiría de la moderna muerte de Dios sólo podría ser contrarrestado mediante la figura extrema del Übermensch, el ultra-hombre; sólo a éste sería dado el ejercicio de lo que Nietzsche llama "amor fati", la apropiación, siempre desde el borde del abismo, del propio destino ${ }^{28}$.

En el mejor de los casos, la filosofía de la existencia es nihilismo activo, voluntad de orden orientada hacia el despliegue planetario de la técnica. Privado de esta posibilidad, el nihilismo de Schmitt no puede ser más que una reivindicación de autenticidad para uso de individuos aislados. Por ello, y no obstante su reiterado alegato a favor de un pensamiento fundamentado en la situación concreta, El concepto de lo político pasa por alto la fundamental co-pertenencia entre el estado de naturaleza hobbesiano y la racionalidad de la modernidad capitalista. Y pasa por alto también las formas que asume la política en una sociedad de masas: la muy concreta manipulación de las masas mediante la propaganda tecnologizada, de la cual el nacional-socialismo hizo un uso particularmente eficaz. Y lo mismo sucede con su recurso a la guerra como catalizador de la seriedad en la vida humana: en la guerra moderna el combatiente concreto es masa de maniobra, carne de tecnologizado cañón, no el héroe en torno al cual se recompondría la mítica comunidad.

Casi al finalizar su Comentario, Strauss pone atención en un párrafo de El Concepto de lo político que considera especialmente sugerente. Escribe Schmitt

Si [...] desapareciese hasta la eventualidad de la distinción entre amigo y enemigo, en tal caso lo que habría sería una concepción del mundo (Weltanschauung), una cultura, una civilización, una economía, una

27 "En la muerte, el Dasein mismo, en su poder-ser más propio, es inminente para sí... Cuando el Dasein es inminente para sí como esta posibilidad de sí mismo, queda enteramente remitido a su poder-ser más propio... La muerte es la posibilidad de la radical imposibilidad de existir" (Daseinunmöglichkeit). La muerte se revela así como la posibilidad más propia, irrespectiva e insuperable. Como tal, ella es una inminencia sobresaliente" (HEIDEGGER, 1998, p. 250).

28 "Mi fórmula para expresar la grandeza en el ser humano es el amor fati: no querer que nada sea distinto ni en el pasado ni en el futuro ni por toda la eternidad. No sólo soportar lo necesario, y menos aún disimularlo - todo idealismo es mendacidad frente a lo que es necesario, sino amarlo" (NIETZSCHE, 1988, p. 203). 
moral, un derecho, un arte, un esparcimiento (Unterhaltung), etc., purificados de política (politikreine), pero no habría ya ni política ni Estado (SCHMITT, 1998, p. 83).

Strauss observa con atención esa serie (cultura, civilización, economía, moral, derecho, arte, esparcimiento, etc.); la lee, no como un mero listado, sino como una serie ordenada, orientada hacia un último término como a su fin último. Por intermedio de lo 'interesante', Weltanschuung y cultura, esferas que incluyen a todos los demás términos de la serie, alcanzarían su culminación nihilista en el mero esparcimiento ${ }^{29}$.

Strauss comparte estas aprensiones de Schmitt; discierne en ellas la falta de un fundamento, ya no político, sino moral, capaz de contener este derrumbe. Por cierto, tal sa moral no podría ser ya un producto del mundo moderno; Strauss la buscará en los filósofos griegos. Aquí nuestros caminos divergen. Porque nadie tiene una suerte de "línea directa" con el mundo griego; accedemos a él a través de una lectura, necesariamente mediada por problemáticas reconstrucciones filológicas, por traducciones e interpretaciones, por intereses que se expresan en el campo intelectual; también por todo un aparato de producción y circulación del saber. "Volver a los griegos" es una posición netamente moderna, al servicio de la elaboración de ideas que se incorporan al debate moderno; ideas, en el caso de Strauss, conservadoras: sólo en el conservadurismo encuentra Strauss un antídoto a las ideas de Strauss.

Pero es posible también prescindir de antídotos, de paliativos ante el nihilismo que Schmitt condena, pero que hace suyo sin saberlo. Por esa vía, la cuestión del esparcimiento se revela como la ultima ratio del pensamiento de Schmitt: intentando superar "la asombrosamente

29 Strauss (STRAUSS, 2008, p. 159-160), Ilama la atención sobre la aparición del término "interesante" (interessant, "del mayor interés" en la traducción) en el escrito de Schmitt, y muy particularmente en el siguiente pasaje: "Un mundo en el que se hubiese eliminado por completo la posibilidad de una lucha de esa naturaleza, un planeta definitivamente pacificado, sería pues un mundo ajeno a la distinción de amigo y enemigo, y en consecuencia carente de política. Es posible que se diesen en él oposiciones y contrastes del mayor interés, formas muy variadas de competencia e intriga, pero lo que ya no tendría sentido sería una oposición en virtud de la cual se pudiese exigir a los hombres el sacrificio de sus vidas, dar poder a ciertos hombres para derramar sangre y matar a otros hombres" (SCHMITT, 1991, p. 35). 
consistente sistemática del pensamiento liberal", pero a la vez internalizándola decisivamente, Schmitt ha terminado por hacer de la misma política una forma de esparcimiento para gustos refinados: un deporte de alto riesgo.

En su Romanticismo Político (1919; 2a edición revisada, 1925), Schmitt criticó ácidamente al romanticismo alemán (con Schiller, los hermanos Schlegel, Novalis y Adam Muller como algunos de sus exponentes destacados) y, a través de ellos, a sus herederos estético-políticos de la segunda mitad del siglo XIX y comienzos del XX. Schmitt hacía ver allí como el romanticismo quiso estetizar la totalidad de las esferas de la vida, incluyendo a la política, traspasando a ellas la idea de una infinitud de posibilidades, y de la 'ocasión' que habría de permitir dar a ellas una forma ${ }^{30}$. Escribe Schmitt:

La contradicción entre limitación racional y plenitud irracional de posibilidades es eliminada románticamente, pues frente a la realidad limitada se oponía otra realidad igualmente real, pero todavía ilimitada: frente al estado racionalista-mecanicista, el pueblo infantil, frente al hombre ya limitado en su ocupación, el niño que juega con todas las posibilidades, frente a la clara línea de lo clásico, la primitividad infinitamente ambigua (SCHMITT, 2000, p. 131) ${ }^{31}$.

Schmitt cita también allí un fragmento de Novalis, en quien se encontraría, escribe, la "verdadera forma del romanticismo": "Todas las casualidades de nuestra vida son materiales con los que podemos hacer lo que queramos, todo es el primer eslabón de una cadena infinita" (SCHMITT, 2000, p. 146. El fragmento citado es el 66).

¿Habrá vuelto Schmitt alguna vez, en los años 1930, o más adelante, sobre este escrito? De haberlo hecho, se habría encontrado con la imagen de sí mismo, como su más propio, su más íntimo enemigo. De sí mismo, no como el implacable realista que imaginaba ser, sino como romántico anti-romántico. Así, armado de su “concepto de lo

30 (SCHMITT, 2000). En términos filosóficos, Schmitt remite al romanticismo al ocasionalismo de Malebranche.

31 Schmitt se refiere aquí, más precisamente, a la apropiación romántica de la infancia, tal como tiene lugar en Schiller ("Sobre poesía ingenua y sentimental") y, cabría agregar, contemporáneamente en Giorgio Agamben (AGAMBEN, 2003). 
político", Schmitt fantasea con dar caza a la compleja realidad del "estado racionalista-mecanicista" mediante la articulación de un pueblo abstracto: "amigos" enfrentados a un casual "enemigo" dando acceso, a la manera de Novalis y su "verdadera forma del romanticismo", al anhelado infinito.

\section{Referencias}

AGAMBEN, G. Infancia e historia: destrucción de la experiencia y origen de la historia. Buenos Aires: Adriana Hidalgo, 2003.

BARNOW, J. “Le vocabulaire du conatus”. In: ZARKA, Y. C. (ed.). Le vocabulaire de Hobbes. Paris: Librairie Philosophique J. Vrin, 1992. p. 103-124.

FOISNEAU, J. L. Hobbes et la toute-puissance de Dieu. Paris: Presses Universitaires de Frances, 2000.

GILLESPIE, M. A. The Theological Origins of Modernity. Chicago/London: The Chicago University Press, 2008.

HEIDEGGER, M. “La época de la imagen del mundo”. In: HEIDEGGER, M. Caminos de bosque. Madrid: Alianza Universidad, 1995. p. 75-109.

HEIDEGGER, M. Ser y Tiempo. Santiago de Chile: Ed. Universitaria, 1998.

HEIDEGGER, M. Nietzsche. Madrid: Ariel, 2013.

HOBBES, T. De Corpore. In: The English Works of Thomas Hobbes Collected and Edited by Sir William Molesworth, v. I. London: John Bohn, 1889.

HOBBES, T. Leviatán. O la materia, forma y poder de una república eclesiástica y civil. México DF: FCE, 1980.

KANT, I. Crítica de la Razón Pura. Madrid, Alfaguara, 1978.

MARDER, M. Groundless Existence. The Political Ontology of Carl Schmitt. New York/London: Continuum Press, 2010. 
MILLER, J. A. "Extimité". In: BRACHER et al. (ed.). Lacanian Structure of Discourse: Subject, Structure, and Society. New York: New York University Press, 1994. p. 74-87.

MONOD, J. Le hasard et la nécessité. Essai sur la philosophie naturelle de la biologie moderne. Paris: Éditions du Seuil, 1970.

NIETZSCHE, F. Werke. Kritische Gesamtausgabe, Berlin/New York: de Gruyter, 1967, VI.3 ‘Dyonisos Dythiramben'.

NIETZSCHE, F. La gaya ciencia. Madrid: Akal, 1988.

NIETZSCHE, F. "On Truth and Lie in an Extra-Moral Sense". In: NIETZSCHE, F. The birth of tragedy and other writings. Ed. R. Geuss; A. Nehamans. Cambridge: Cambridge University Press, p. 139-153, 1999.

POPKIN, R. La historia del escepticismo, desde Erasmo hasta Spinoza, Mexico DF: FCE, 1983.

SCHMITT, C. Der Begriff des Politischen. Berlín: Duncker \& Humboldt, 1991.

SCHMITT, C. Roman Catholicism and Political Form, Westford, Connecticut/ London: Greenwood Press, 1996.

SCHMITT, C. El concepto de lo político. Madrid: Alianza Ed. 1998.

SCHMITT, C. Romanticismo Político. Buenos Aires: Universidad Nacional de Quilmes Ediciones, 2000.

SCHMITT, C. El Leviatán en la teoría del estado de Thomas Hobbes, Buenos Aires: Ed. Struhart \& Cia, 2002.

SCHMITT, C. "La science allemande du droit dans la lutte contre l'esprit juif". Cités, v. 14, p. 173-180, 2003.

SCHMITT, C. Teología Política. Madrid: Trotta, 2009.

STRAUSS, L. "Comentario sobre el concepto de lo político, de Carl Schmitt". In: MEIER, H. Carl Schmitt, Leo Strauss y El concepto de lo político. Sobre un diálogo entre ausentes, Buenos Aires: Katz, 2008. p. 133-170. 
VON HAYEK, F. A. "The Use of Knowledge in Society". The American Economic Review, v. 5, n. 4, p. 519-530, 1945.

WITTGENSTEIN, L. "A Lecture on Ethics". In: The Philosophical Review, v. 74 n. 1, p. 3-12, 1965.

ZARKA, Y.C. "Le mythe contre la raison: Carl Schmitt ou la triple trahison de Hobbes". In: ZARKA, Y. C. Carl Schmitt ou le mythe du politique. Paris: Presses Universitaires de France, p. 47-70, 2009.

ZARKA, Y. C. "El mito contra la razón. Carl Schmitt o la triple traición a Hobbes", In: ZARKA, Y. C. Carl Schmitt o el mito de lo político. Buenos Aires: Nueva Visión, p. 37-54, 2010.

Recebido: 13/04/2017

Received: 04/13/2017

Aprovado: 19/07/2017

Approved: 07/19/2017 